Pre-publication version of:

Goodings, L. (2012). Understanding Social Network Sites: Lessons From MySpace, Visual Communication, 11(4), 485-510.

\title{
Understanding Social Network Sites: Lessons from MySpace
}




\begin{abstract}
MySpace.com is an online social network site (SNS) where users build a 'profile page' to communicate with millions of other users all over the globe. MySpace users customise their profile page with words, photographs, pictures, music, biographical information and other visual/textual icons. There are a number of unique practices that are inherent to these new online social spaces that extend from the need to maintain a personal profile. For example, many users will regularly update their profiles with new visual or textual information (a practice that will be identified as 'profile changing'). However, over the last few years MySpace has experienced a decline in terms of the numbers of users that visit the site. This article takes a historical look at the use of MySpace in order to explore some wider issues in online communication practices. Through an empirical analysis of 100 open-access MySpace profiles, this paper will examine the use of SNSs in relation to issues of self, community and wastefulness. This work also addresses the ongoing need to blur the boundaries of visual/textual, online/offline, reality/representation and social/psychological in the way we understand the relationship between human experience and technology.
\end{abstract}

\title{
KEY WORDS
}

Mediated Community - MySpace - Process - The Visual and The Textual • Wastefulness • The Internet • The Self 


\section{INTRODUCTION}

MySpace.com is an online social network site (SNS) where people can communicate in a variety of different ways. MySpace users are able to meet with people all over the globe and interact through a number of different means (e.g. blogs, wall posts, photo comments etc.). MySpace was launched in 2003 and seemed to have a unique interest in music culture and the ability for users to customise their page (boyd, 2007). Rupert Murdoch's News Corporation bought MySpace in 2005 for a staggering $\$ 580$ million when MySpace was at its peak at a time when large number of users seemed to be joining MySpace en masse.

However, more recently, it appears that MySpace has witnessed a high number of users leaving the site. As a result, MySpace has recently ranked $87^{\text {th }}$ most trafficked website in the world (Alexa.com, 2011). In 2011, News Corporation sold MySpace for \$35 million which could serve as evidence that the site is officially 'dead'. The decline of MySpace use could also be linked to a range of other SNS-type technologies that offer a similar set of social functions and capabilities. Twitter, for example, is a micro-blogging website where users post short textual messages or 'tweets' to a network of other users. Twitter users regularly keep their audience updated with their current activities, views on a recent events or general news and information. Therefore, online users are increasingly becoming distributed across a range of platforms and they are less dependent on the information from one location (Marwick and boyd, 2010). 
Therefore, the MySpace decline could be indicative of the way that people are now distributed across a number of online locations.

In Alone Together: Why we expect more form technology and less from each other, Sherry Turkle (2011) discusses this multiplicity of communication technologies and the sense of distance and detachment that is inherent in the use of new technologies. Turkle explains how there is an increased experience of vulnerability and isolation in which 'we are increasingly connected to each other but oddly more alone: in intimacy, new solitudes' (2011: 19: original emphasis). This book shows how new forms of communication, such as Facebook and Bebo, all include the need to be constantly connected to a huge number of other online users, but rather than gaining a sense of connection from these multiple relations we are growingly experiencing a lack of any 'authentic' feelings ${ }^{1}$. Harper (2010) also argues that we both love and loathe our increasingly connected relationship with technology.

However, given this level of multiplicity, Turkle (2011) still asserts that our ability to be manifold beings does not challenge the ability to feel a sense of wholeness or unification in our experience. Turkle states that it is essential that these sites encourage a level of multiplicity in order for us to feel 'ourselves' (2011: 194). The self in then treated as a process that is constituted across a number of spaces and relations: a form of experience that is continually unfolding and changing. This idea is continued from one of Turkle's earlier books, Life on The Screen (1995), where she was one of the first to recognise how cyberspace showed that the self is characterised by ongoing change and fluidity (also linked to the ideas of postmodernism). This conceptualised the self as part of a multiplicity of selves where people are able to manoeuvre between different forms of online and offline selves. Turkle argues that offline selves and online selves are not separate, but tangled and interwoven in our everyday experience, as one of her 
participant's notes, 'RL [real life] is just one more window' (1995:13). This shows the power of the online environment to provide a space where people can experiment and 'recreate' oneself on the screen.

However, in Alone Together there is a sense that this overall feeling of experience is now layered with new forms of complexity. For Turkle, many of the new technologies are imbued with new feeling of solitude, isolation and separation. For many these new forms of multiplicity produce a new set of tensions and complexities and as Turkle writes - 'in intimacy, new solitudes'.

\section{PROFILE CHANGING AND THE ONLINE SELF}

The real strength in Sherry Turkle's work is how her ideas have spanned a number of years and a range of different technologies. Clearly, the use of a historical perspective has given Turkle a real clarity and precision to her argument. In a similar vein, this paper aims to make use of a historical perspective in studying MySpace, admittedly not on the same scale, but with the intention of being able to investigate the underlying practices through an examination of MySpace use. In doing so, the aim is to offer some commentary on the current use of SNSs and other forms of communication.

This study is focussed on the use of MySpace in 2007. At this time many MySpace users would regularly update their profiles with new information, songs, texts, images and photographs. Users had the choice as to whether they make their profile 'public' or 'private' and this would impact on the ability to see certain aspects of the profile (profiles can be restricted by making them 'friends only'). Many users made friends MySpace by meeting people through the 
'browse' function (where people are able to scroll through the members of MySpace in terms of a set of criteria: age, gender, sexual orientation, what they are 'here for' etc.).

Each profile page would carry a main photograph (also referred to as the 'default photograph') that was typically a passport-style photograph of the profile owner. This photograph acted as a symbol of the profile page and featured in other forms of MySpace communication, for example, alongside wall comments and photo comments. MySpace users were able to personalise their profiles through the organisation of the visual and the textual elements of the page. 'Profile changing' defines this process of updating or modifying the different aspects of the profile: ranging from a large scale change (e.g. a change to the entire profile background) to a small scale change (e.g. a change to the mood setting or song choice). Many scholars identified that power of the profile page and commented how their role was integral to the construction of the self in SNSs (boyd and Ellison, 2007; Gross et al., 2005).

During this time, Boyd and Heer (2006) argued that an 'online body' was created and sustained through the text in the profile page. From this perspective, the online body was brought into being through the interpretation of the words on the screen as a set of semiotic resources. The use of such resources provided a way of transgressing the problems associated an online connection, for example, a lack of a shared physical location or the ability to connect with a visible audience (boyd and Ellison, 2007).

As MySpace grew a wealth of literature documented the way an online self could be understood through Goffman's (1959) notion of 'presentation of self' (for example see Bargh, McKenna and Fitzsimmons, 2002; Cheung, 2000; Robinson, 2007; Siibak, 2009; Whitty, 2008; Wynn and Katz, 1997). Following this perspective, the online self is conceptualised by means of a 'dramaturgical' metaphor: whereby, Goffman's ideas could be mobilised to understanding the 
way people strategically present themselves in a way that will seem plausible to the other members of the online community. Throughout an interaction, the self is invoked in particular ways as to corroborate with other selves. This shows a pragmatic notion of the self that explains how individuals try to create, be it consciously or unconsciously, a response to the context of their surrounding environment. The research that uses this theory in understanding the online self is characteristically interested in the way that different online users are able to interpret language and gestures as signs and symbols.

However, the developments to Goffman's ideas have been overlooked in the application of these ideas to the study of the online communication (and potentially other places). For example, Rom Harré (1983) developed Goffman's dramaturgical understanding of the self in order to reduce the emphasis the 'actor' behind the mask. This research is rarely adopted in relation to the study of online phenomena but has vast implications for how the dramaturgical notions of the self could be understood and deployed in the online setting. Harré explains how individuals are more like the 'director' of a theatrical performance and states that individuals have the ability to be jointly concerned with both performance and critique. Thus, the self includes a number of contradictions and inconsistencies that occur at the site of interaction. Such an approach aims to close the gap between the social and the psychological in promoting a nondualistic version of the self that is not divided into front and back stage.

Harré's work could be connected with the 'linguistic turn' that originated in the 1980s from which there has been a tendency to focus on the function of language and the complex way that human beings use communication to understand their social world. Discursive Psychology (DP) focuses on the way language becomes the main way for both describing and understanding the world (Edwards and Potter, 1992, Gergen, 1994; Potter and Wetherell, 1987). DP is then 
primarily concerned with the function of talk and text and includes the traditions of discourse analysis (DA) and conversation analysis (CA). Both of which utilise a fine-grained investigation of the way that language is used to mobilise a range of social actions. For example, DA is interested in the instances where people construct themselves as a member of a particular social category: the subtle processes the people regularly engage with in order to establish their position as one who is accountable to a certain social group (Potter, 1996). This field of research is of interest to the ability to understand the online self and there have been many attempts to study online talk using a discursive methodology (Antaki et al., 2006; Goodings, Locke and Brown, 2007).

In a recent study of MySpace, Van Doorn (2010) explores the ways that a network of friends uses a range of semiotic resources to bypass gender-normative practices of sexuality. Van Doorn (2010: 598) argues that 'affection can be conceived as flowing through the network as it is continuously (re)assembled and (re)distributed in accordance with the specific social context in which the exchanges are embedded'. This work shows how MySpace users are able to access a different kind of self in the process of communication of different semiotic resources. In following these ideas there is a need to move beyond Goffman in order to explicate the way our experience is based on an entangled and intertwined set of selves. This encourages a focus on complexity and fluidity of the shared social reality that is present in any MySpace interaction (see also Booth, 2008).

\section{THE VISUAL AND THE TEXTUAL}

However, in concentrating on the linguistic power of communication in SNSs little attention has been made to the visual aspects of communication. In fact, few studies into the SNSs have 
explored the power of the visual or, perhaps more importantly, the way that the visual and the textual work together at the site of communication. Visual methods are growing in popularity and they show how the use of photographs, videos and other visual-based methodologies can be analysed in a number of ways. Furthermore, visual data is frequently used in ethnographic investigations as a way of evidencing a particular culture or phenomenon (Knoblach et al., 2008; Pink, 2007, 2008). Much of this work builds on the broader success of using visual methodologies in sociology and social anthropology. These areas also build on the field of semiotics where there is an interest in the production of meaning-making through visual symbols (Barthes, 1967, 1991). As a result of the overindulgence in the textual aspects of the communication, there have been several attempts to combine DA with a range of visual analyses (see Greiffenhagen and Watson, 2009; Norris, 2002). However, this work has been criticised for the way it views the visual as a supplementary function of the spoken communication (see Bohnsack, 2008; Norris, 2002).

Jewitt et al. (2002) state that communication is essentially 'multimodal' and should therefore be studied in such a way. Multi-modal analysis accepts different layers of communication without overemphasising one dimension or another (see Bezemer and Jewitt, 2009; Jewitt, 2009). Furthermore, with regard to the specific use of a computer (or other media devices), Jewitt and Triggs (2006) argue that information which is presented to us on the screen shows how people are able to mediate information and establish a shared sense of experience through the communication. Therefore, in an attempt to utilise an equal relationship between the visual and the textual this paper will use the teachings of Michel Foucault.

In This Is Not A Pipe (1982), Foucault explores the multiplicity of the visual and the textual a discussion of a painting by René Magritte. The painting shows a picture of a pipe with 
the words 'Ceci n'est pas une pipe' (This is not a pipe) written underneath. Foucault discusses how the painting exposes our conceptions of things and signs to show how both the visual and the textual can be treated as instances of power. For Foucault, there is no resolution to the difference between the words in the painting and the image of the pipe. In fact, it is precisely this unsteadiness between the visual and the textual that is present in our everyday encounters with pictures and words. Foucault argues that words should not be understood as supporting the visual or vice versa, but rather that the mixing of different elements, of words and pictures, provides the basis of our experience (for further discussion, see Brown, 2001; Brown and Stenner, 2009). This unites with the growing need to understand the visual in psychology (Reavey, 2011) and could further aid the retrospective exploration of communication in MySpace.

\section{MEDIATED COMMUNITY}

So far, this paper has considered a number of keys issues that are important to the study of MySpace, including the self and the visual/textual. However, there is one further concept that is crucial to this debate - community. Rheingold (1993) first used the term 'virtual community' to explain how cyberspace could act as a space for shedding the confines our offline lives and moving to a space of unlimited possibility and opportunity (see also Leary, 1999; Plant, 1997). However, given the everyday use of online communication technologies there are no reason to understand a virtual community as warranting some kind of special status or position.

Furthermore, this approach avoids the possibility that community is something which could be felt or experienced.

In order to access this felt notion of community it is necessary to look outside of the notion of a virtual community. Lave and Wenger (1991) define a community in terms of a shared 
sense of practices where the formation of these shared meanings is culturally, historically and contextually dependent. From this perspective, communities are defined by a collective set of practices as opposed to the essential qualities of the group (their shape or size, for example). In Imagined Communities, Anderson (1983) describes the way that people participate in a range of extreme activities based on a shared sense of belonging. This distinction is particularly useful in the study of MySpace as it also includes an explanation of how people feel attached to their social group without a need for regular contact: the imagined community. Anderson writes:

It is imagined because the members of even the smallest nation will never know most of the fellow-members, meet them, or even hear of them, yet in the minds of each lives the image of their communion. (Anderson, 1983:6)

The above quote shows the imagined community is not considered to be in the minds of the individuals but in the social practices of the community. This does not imply that there is no psychological element to the imagined community, rather that the psychological and the social are constituted at the point of interaction. The imagined presence of a community in MySpace organises a specific set of social practices. Each user is connected to a network of other users who may provide a potential source of communication. However, it is important that this definition does not state that people will act in any predetermined sense. The community is treated as just there due to the way that the users have to act into the community in order to create meaning. It is then in each interaction that the negotiation of what it means to be in that community is created and maintained. Thus, the community is continually changing in relation to an imagined set of relations and a current set of social practices. This idea is fitting for the study 
of MySpace as many users will have many more friends than one person could reasonably expect to maintain any real sense of friendship with (e.g. some users have hundreds of thousands of friends) and therefore there is a strong potential for an imagined connection between the users.

This paper defines MySpace as a 'mediated community' in order to capture the unique way that MySpace facilitates the production of a shared set of practices in a way that is not dissimilar from any other sort of community (e.g. in an offline setting). Mediated community emphasises the specific practices that are unique to MySpace defines the particular modality in which the mediation occurs in MySpace. The modality is provided by the distinctive way that MySpace users design and re-design who they are and who they are friends with. This includes something of an imagined element of community due to the high number of relatively weak social ties.

Marwick and boyd (2010:124) follow a similar line of question in looking at the microblogging site Twitter where they argue that the community presence has a direct impact on the way people use Twitter to the extent that 'the imagined audience affects how people tweet'. Marwick and boyd also address the issue of distribution across a number of different platforms where they argue that people are able to 'collapse' different audiences into a singular set of actions. However, one essential difference between the way Marwick and boyd (2010) conceptualise the imagined audience and the current use of mediated community is that the former is positioning the audience as 'cognitively constructed' (boyd, 2006b). Alternatively, the latter is focussing on a performance of community that is located at a social level. Clearly, in order to understand the notion of imagined or mediated community there is a need to blur the social and the psychological in order to examine the complexity of profile changing in MySpace. 


\section{DATA COLLECTION, ETHICS AND ANALYSIS}

The data for this analysis is taken from two open-access profiles from MySpace in 2007. A total of 100 MySpace profiles were initially gathered using the MySpace 'browse' function. The search initially returned over 3,000 hits from using the following search terms: age - 'between 18 and 35' (the default setting), location - 'UK' and what are you here for - 'networking'. The term 'networking' was chosen in order to search for active members in MySpace. The profile changes of 100 MySpace users were observed and recorded over a period of one month $(n=100)$. The sample included 61 males and 39 females, aged between 18 and $39^{2}$. The URLs from the original search were stored on a computer and the data was recorded by visiting the profile pages each day and taking a screenshot of the entire profile page. This data collection had to be conducted over a short period of time because in MySpace (as with other SNSs) the links to other profiles can very quickly become 'old' or 'broken'. This method also allowed for the capture of a higher amount of contextual information by following one strand of profile changes over a short period of time.

All forms of identifying information have been deleted from the profile screenshots. The names that feature in this report are all pseudonyms and are designed to conceal the identity of the profile owner ${ }^{3}$. The unique URL to their profile has also been removed in order to block the possibility of searching for the page. In order to allow withdrawal, the MySpace users were sent private messages through their MySpace email accounts which included information on this study. Included in this message was the opportunity to withdraw from the study. None of the 100 participants decided to withdraw from the study as a result of this process (see Davis, 2010 for a similar ethical set of concerns). Hopefully, the time that has passed since gathering this data will also act as a way of protecting the participants further. 
Participants were removed from the study if they changed their profile status to 'private' (or if they deleted the profile entirely) during the data gathering process ${ }^{4}$. This research was able to keep to standard ethical procedures by restricting the involvement of certain vulnerable groups (such as the over 65s and under 18s). Also, during the course of the study, MySpace privacy statements, terms of use and other more general help features, were all monitored to maintain a high knowledge of the ethical issues surrounding the use of MySpace and the Internet more generally. The findings of this investigation have been treated with a high level of social sensitivity and any information that was felt to be potentially damaging was immediately destroyed. The cookies/web page addresses were all deleted from the system once the data had been gathered. There is the possibility that other academic researchers could populate the site but given the way this paper is taken from a time when user figures where at its highest it is unlikely that any academics would feature in a random sample.

The study of MySpace and of any other form of new technology requires the need to readdress conventional notions of ethics. In this case, the attempt to conduct new forms of research should consider any ethical dilemmas in order to create a space for the research to continue (Griffiths and Whitty, 2010). In studying MySpace it must be remembered that the data was gathered from a space (and time) where there was an emphasis on doing things publicly. MySpace users would post messages, upload videos, create blogs and modify their profiles in a way that was intentionally profile; so much so, that boyd and Heer (2006) labelled the use of MySpace as a 'public identity performance'. In 2007, the time the data was collected, two thirds of MySpace profile pages were found to be world visible (Hinduja \& Patchin, 2008; Thelwall, 2008) and it is therefore reasonable to expect that MySpace users are aware of the public nature of the site. 
It is necessary to maintain a high level of ethical sensitivity by respecting 'participants' expectations of privacy and consider the extent to which observations may have potentially damaging effects for participants (Ess and the AoIR Ethics Working Committee, 2002; Flicker, Haans \& Skinner, 2004). However, Thrift (2003: 108) notices how 'new forms of ethics closes down some of the main means by which we learn about others and other cultures'. This implies that certain areas of research may become restricted in the future due to the power of ethical procedures. This is particularly as issue for SNSs where there is strong potential for ethical decisions to be influenced by the wider mass media (what Marwick, 2008 refers to as a 'technopanic'). Thrift argues, as researchers, we need to expand our subjectivity to take on the experience of those being studied. This involves having a good judgement about what is presented in online environments and always considering issues of privacy and confidentiality.

Each of the 100 profiles was read repeatedly to identify reoccurring aspects of profile changing. A multi-modal analysis was applied to the data by considering both the visual and the textual aspects of the communication. However, even though there is a definite decision to further the use of a purely textual analysis, this study still intends to maintain a 'discursive mentality'; whereby, there is an interest in any form of inconsistency or ambiguity in the interaction - that is, moments where the MySpace users appears to be doing something with the visual or the textual aspects of the page in order to achieve a particular social action.

\section{ANALYSIS}

This analysis will now illustrate the version of the self in question and explore the practice of profile changing in MySpace. The first personal profile is taken from a MySpace user called 'It's a Casual Thing' (or just 'Casual' for the purpose of this report). Casual is a male MySpace user 
who changes his profile three times during the course of this study. Casual is an active user who regularly visits his page and communicates to a number of other users via the site.

\section{Extract 1: Positioning the Self in MySpace}

Figure 1 shows the use of a dimly lit profile photograph that acts to distort the body image and direct the gaze to the other, more vibrant, areas of the profile background. Casual's background consists of a number of brand labels in a colourful arrangement across the entirety of the profile. Casual's profile page includes a tag line that is adjacent to the profile photograph which reads 'Creamfields Aug 25th ... loving it!!' ${ }^{5}$ Each of these activities shows how Casual is able to demonstrate an active status through his profile page and how the potential to encourage future communication can be present in even the smallest aspect of the profile page. For example, another MySpace user might 'reply' to Casual's tag line by commenting on their intention to go to Creamfields. 


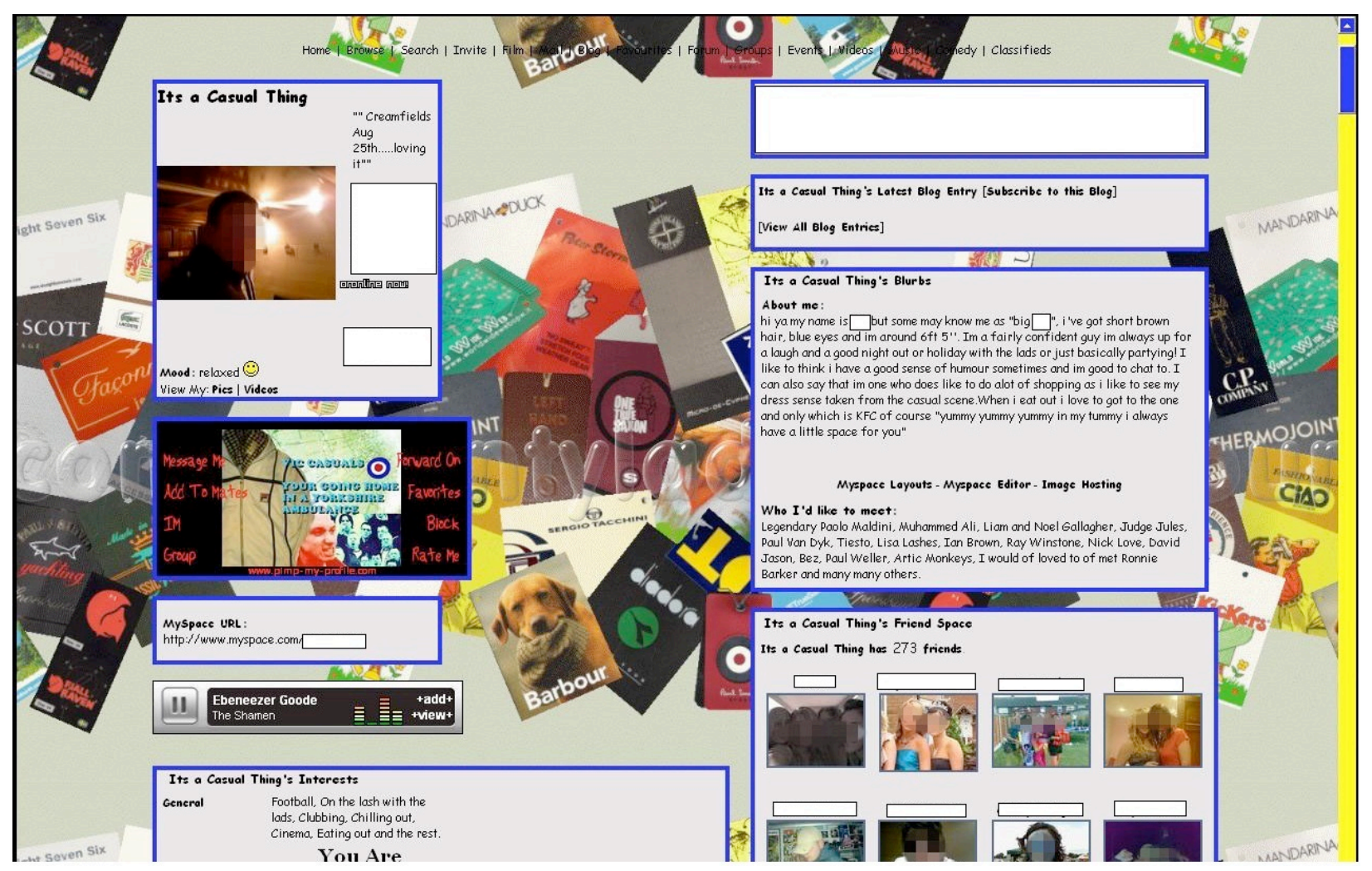

Figure 1 First Screenshot of It's a Casual Thing

Figure 1 shows how the profile name, 'It's a Casual Thing', appears to have a connection with the phrase 'Vic Casuals' in the interactive box. The interactive box is a section of the profile page that is located directly below the profile photograph and includes a number of different ways of contacting the profile owner. Like any other part of a MySpace page, the interactive box can also be customised. Casual's interactive box features a number of references that demonstrate a strong gendered performance, for example, 'your going home in a Yorkshire ambulance'. This statement is localised in place through the significance of it being a 'Yorkshire ambulance' and also performs a wider connection with a male stereotype through the reference to violence and aggression. Therefore, Casual is able to make use of different semiotic resources from different parts of the page to signal a particular formation of the self in MySpace. 
In the 'who I'd like to meet' section of Casual's profile, there is a list of iconic male figures who embody this version of the self, which includes: 'Muhammed Ali', 'Liam Gallagher' and 'Ray Winstone'. This information is connected to the blurb section of the profile where Casual describes himself as a 'fairly confident' person who likes 'a good night out or a holiday with the lads' - again showing a strong performance of masculinity. Extract 1 also shows that Casual has a high number of friends (273 exactly) which would suggest that Casual has an increased level of social status (see Lampe et al., 2007).

The profile activities show a way of 'positioning' Casual's self in MySpace. Social positioning explains the way people are able to discursively identify themselves with a particular social category (Davies and Harré, 1990; Harré and Langenhove, 1999). From this perspective, the self is then dependent on the way a person is positioned in any given interaction and explains the way people are different from one identity category to the next (e.g. a school child may act very differently when in the presence of a teacher as opposed to his/her friends). The self is accomplished and negotiated through the shaping of the interaction to achieve a particular position within a group (see Harré, 1998). Figure 1 shows how Casual is signaling a membership to a particular social group that shares a similar set of values in relation to the performance of masculinity. Therefore, Figure 1 shows how Casual is concerned with articulating his position within an imagined network of MySpace users. The following screenshot shows the first set of changes that Casual makes to his profile: 


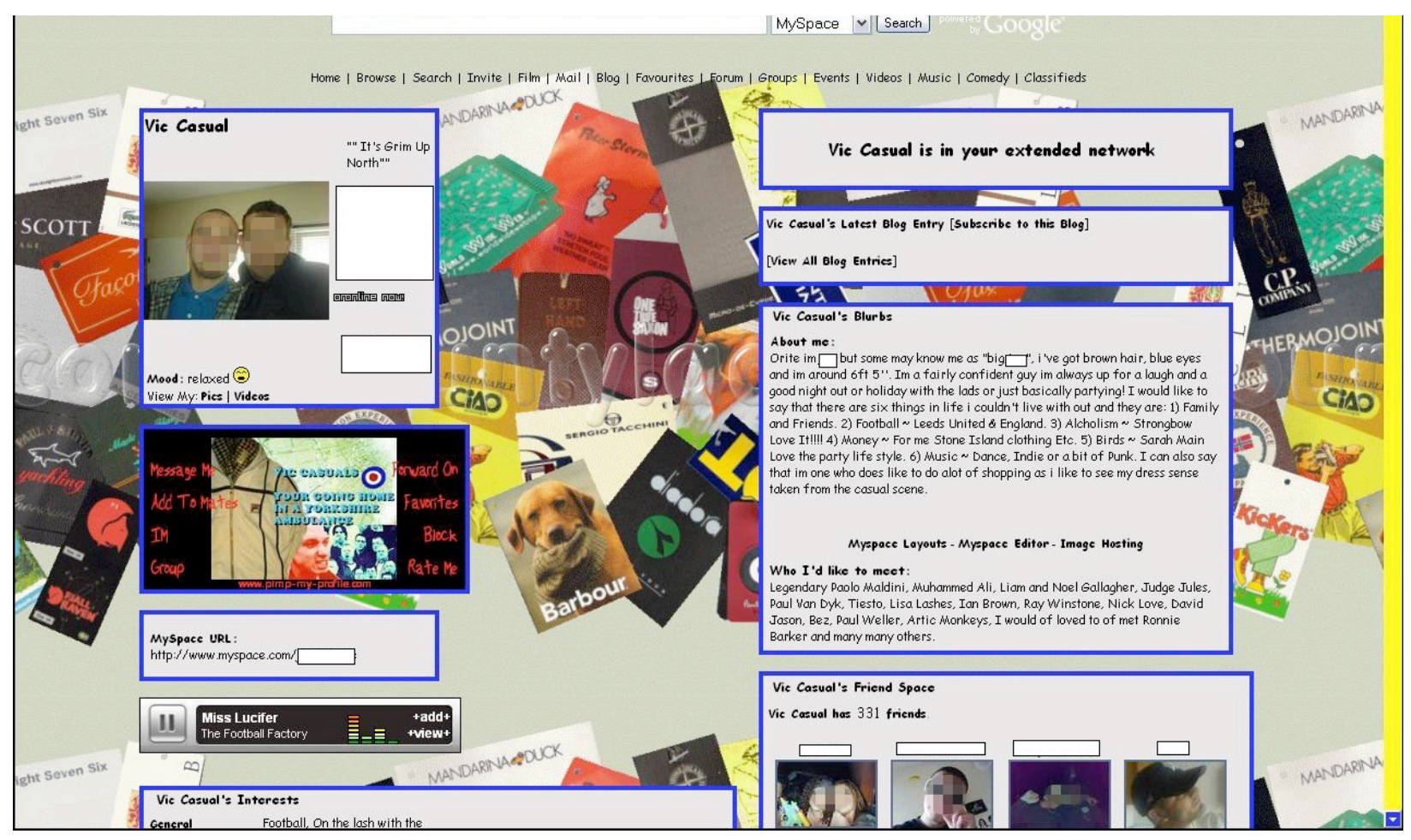

Figure 2 Second Screenshot of It's a Casual Thing

Figure 2 shows the changes to Casual's profile of which the first noticeable change is that the display name has been changed to 'Vic Casual' (a phrase that was previously found in the interactive box). This shows that users are able to make connections across different profiles in time. The profile picture has also changed to a new photograph of Casual with another male. The jacket that the new male is wearing also appears to match one of the images from the interactive box. This shows a level of interactional binding the ties the different elements of the profile page together.

Figure 2 shows that tag line has been changed from 'Creamfields Aug 25th...loving it' to 'It's Grim Up North' where there is clear difference between the positive construction of 'loving it' to the negativity of being 'Up North'. This could imply a shifting nature of the profile and the subsequent performance of the self. This difference may also be used to signal other, more 
subtle, changes in the profile where without such signals the other alterations may have gone unnoticed by the huge potential of MySpace audience members. Following this line of analysis, it is interesting to note that the blurb section of Casual's profile has been subject to a number of changes, including a list of 'things in life [that Casual] couldn't live without'. The list contains: '1) family and friends 2) Football - Leeds United and England 3) Alcoholism - Strongbow Love it!!!' The act of clarifying the things he 'couldn't live without' shows that the organisation of the profile is hinged on the way that the profile is received by a particular group of people.

However, this is not to suggest that the change commands the community to act in a particular way. Clearly, within the attempt to forge a new set of relations (such as the identity on offer in this profile) it is crucial to remember that these profiles are inherently visible to a wide number of users. It could be for this reason that the reference to 'friends and family' still appears as the first item of Casual's 'list'. Even if the other members do not look at these subtle changes that Casual makes, there is imagined sense of mediated community that is invoked in the process of profile changing.

It may be of importance that Casual does not change any of the people in the 'top 8' section of his profile. The 'top 8' section of the profile has been identified as an important aspect to the function of friendships in MySpace (boyd, 2006a). It has also been suggested that being 'dropped' from the top 8 can have links with low self-esteem and other negative feelings. The final set of changes to Casual's profile show a more dramatic set of changes to the profile. Here is the screenshot of the changes: 


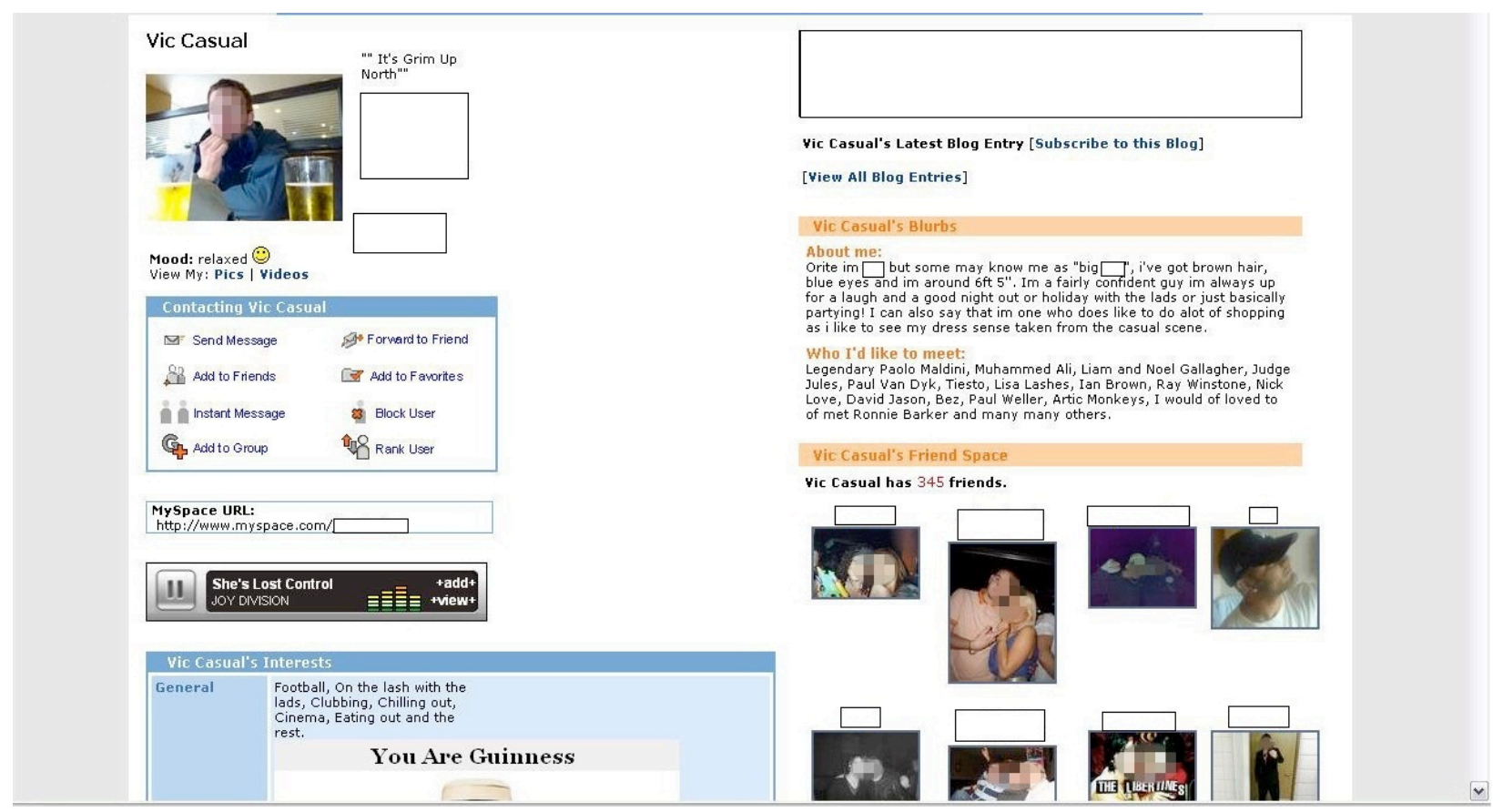

Figure 3 Third Screenshot of It's a Casual Thing

Figure 3 shows how Casual has completely removed the profile background from the profile. The page has been left with a plain white background (the default setting) that signifies a withdrawal from the earlier profile pages. This symbolises a shift in the construction of the self and a removal of the masculine identity category.

Therefore, the self in MySpace is clearly always in process - moving from one position to another - where with each change the self in MySpace is able to accommodate an alternative subject position. This offers the MySpace user an opportunity to visit a different form of the self and feel connected under a different set of conditions. In Figure 3, Casual's profile is moving from one version of the self to another, where there is a need to wipe away that last set of identity markers in order to perform the self once again. Casual's profile is in a state of flux where a new direction to the self is waiting to be applied to the profile. 
During this process, Casual's number of friends has increased from 270 to 345 . This implies that an imaginative skill to profile construction could lead to a higher number of friends through the ability to demonstrate membership to a range of possible mediated communities. Figure 3 shows the practice of constituting the self in a multiplicity of ways through a potential set of relations. Through the practice of changing the words and images on the page the users are able to organise their membership to a range of communities in MySpace. This membership is a complex process that involves a number of overlapping communities and relies on subtle negotiation of the visual/textual aspects of the page in order to ground communication in a particular way.

\section{Wastefulness in MySpace}

However, it could also be argued that a great amount of these changes to the profiles have a high potential to go unnoticed. What if the other members of the mediated community do not notice any of these changes? In The Ecstasy of Communication (1988), Jean Baudrillard conceives a technological space where people are so heavily interested in their own appearance that others almost cease to exist (see also Lanier, 2010). For Baudrillard, the rise of different forms of communication technology offers the opportunity for an individual to constantly reproduce themselves constitutes the 'death of expression'. Baudrillard (1988: 29) writes, 'what matters above everything else is proving our existence, even if that is its only meaning'. Even though this work is not specifically targeted at SNS, there is some similarity in the way that the data has shown the basic, emotionally disconnected relationship where someone is obliged to keep updating their profile: It simply states that I am here. 
Baudrillard (1988) speaks of a shift towards using modern forms of technology as a way of presenting the self and describes a space where people are so heavily interested in their own appearance that others almost cease to exist. For Baudrillard, the rise of different forms of communication technology offers the opportunity for an individual to constantly reproduce themselves. Baudrillard (1988: 29) writes, 'what matters above everything else is proving our existence, even if that is its only meaning'. From this perspective, communication facilitates a basic, emotionally disconnected relationship where someone is obliged to accept the existence of another. It is merely demonstrating that ' $\mathrm{I}$ am here'. Baudrillard identifies the way modern technology seems to be littered with a vast amount of unnecessary communication that is dedicated to our own sense of uniqueness. In a similar vein, some view the communication in new technologies as a form of 'phatic communion' (Malinowski, 1923). The argument here is that the communication in many new media technologies generates a vast amount of vacuous, unnecessary forms of communication. This could be evidenced from the number of changes to Casual's profile: whereby, the high numbers of changes to the profile do very little to signal a change in the self.

For Turkle, the constant need to change or update a profile page (or other medium) is indicative of the new levels of isolation or 'solitude' that is inherent in new technologies. This binding of intimacy and solitude could be related to this intrinsic form of wastefulness and the way that a large amount of profile activity is an essential component of everyday communication. This could also be understood as the dilemma between distance and closeness that is inherent in these online social practices (see Goodings, In Press). 
Figure 3 also suggests that there is a need for a high amount of activity (that could be seen as wasteful) as evidence for the way that people must act into the community in order to create meaning. In other words it does not appear to that the community is just there in the way that the audiences automatically affects that way people will act. This offers the opportunity to develop the notion of a mediated community, whereby the community does not automatically affect that way people will act (as with Marwick and boyd's (2010) notion of an 'imagined audience'), but rather that what it means to be a communicated is constantly being negotiated and re-negotiated these profile activities. These claims will be further explored in Extract 2.

\section{Extract 2: The Potential Self in MySpace}

Figure 4 shows a different MySpace user. This time the data relates to the actions of a female user who has a high amount of activity on her profile. Figure 4 shows that Julia (real name has been anonymised) states that 'I am opinionated - but that doesn't make me a bad person, and I'm not fake, but I just can't be...but then again how many times on this site do you hear people quote that'. The use of the marker 'on this site' appears to be of interactional significance as she is positioning herself as somehow different to other forms of interaction. Her blurb begins with the question 'where does anyone start when having to talk about themselves??' This question is juxtaposed to many MySpace practices (e.g. the blog) that requires a form of self-reflection. There is also a playful use of the phrase 'I'm not fake, how can I be...but then how many times on this site do you hear people quote that'. This refusal to construct the profile in a traditional sense creates another way of constituting the self. 


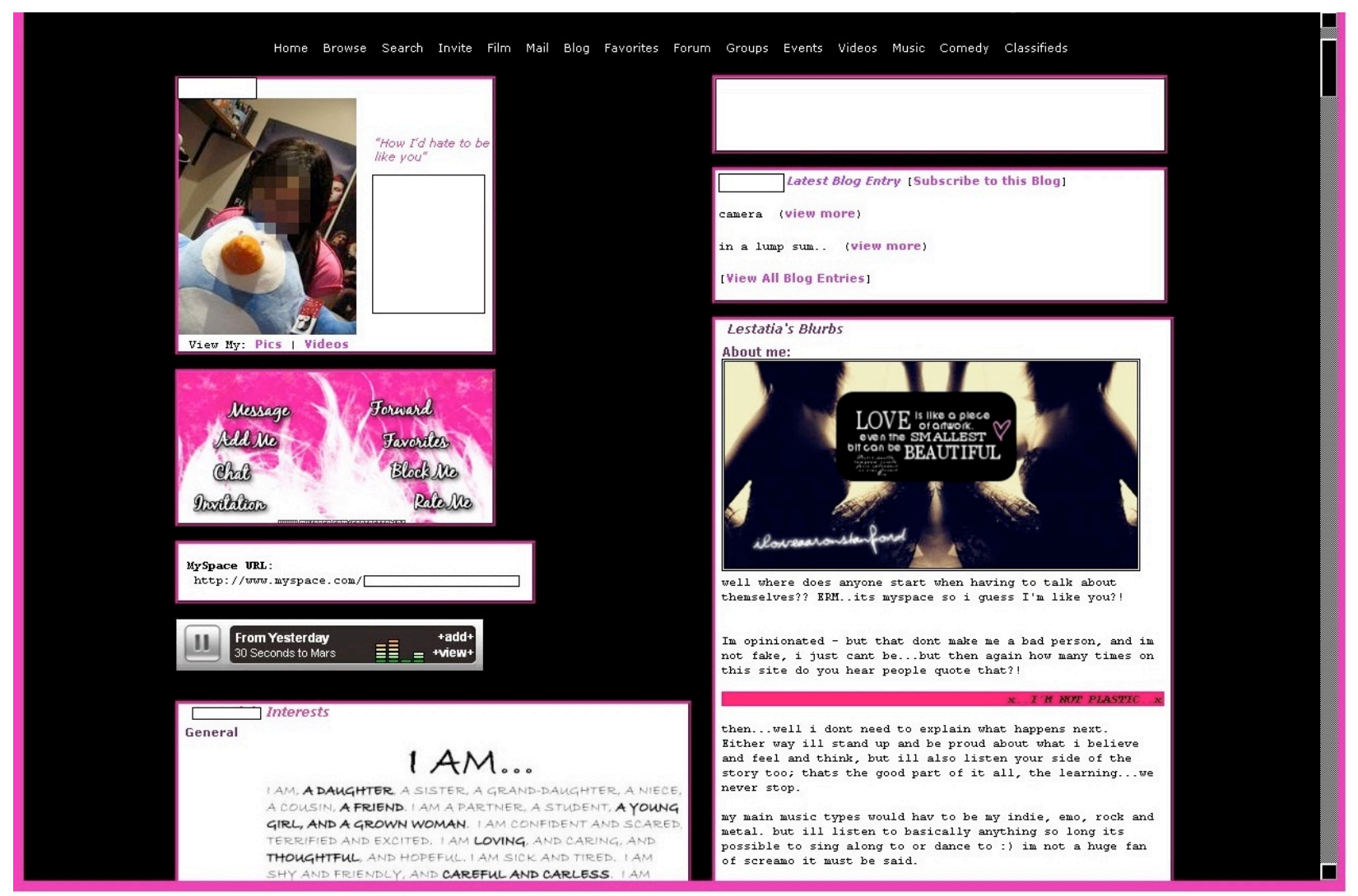

Figure 4 Screenshot of Julia's first profile page

Figure 4 shows the playful rejection of the profiling norms in Julia's personal profile. The construction is intentionally positioned as being different to the rest of the users in MySpace. For example, Julia's display name is 'How I'd hate to be like you' and such a name would suggest distaste for the kind of activity that occurs in MySpace but it is clear from the other sections of the profile that this distance from the other members of MySpace is a way of constituting closeness (for further discussion of closeness and distance in MySpace see Goodings, under review). This distance provides another way of doing identity as with the display of masculinity in Extract 1. 
However, the profile includes a number of inconsistencies; for example, a different location of the page describes her commitment to being a 'loving' and 'caring' person. This shows how self is performed through the power of this contradiction and evidences the idea that the presentation of self does not fit a linear pattern. It is also noteworthy that the text description of her capabilities as a caring person is actually an image: it is picture that has been uploaded to the page in that particular location on the page. This shows the conception of the visual and the textual is not one that can be easily separated in MySpace as there are many textual occurrences on the page that are actually uploaded as a picture. The following changes were made to Julia's profile:

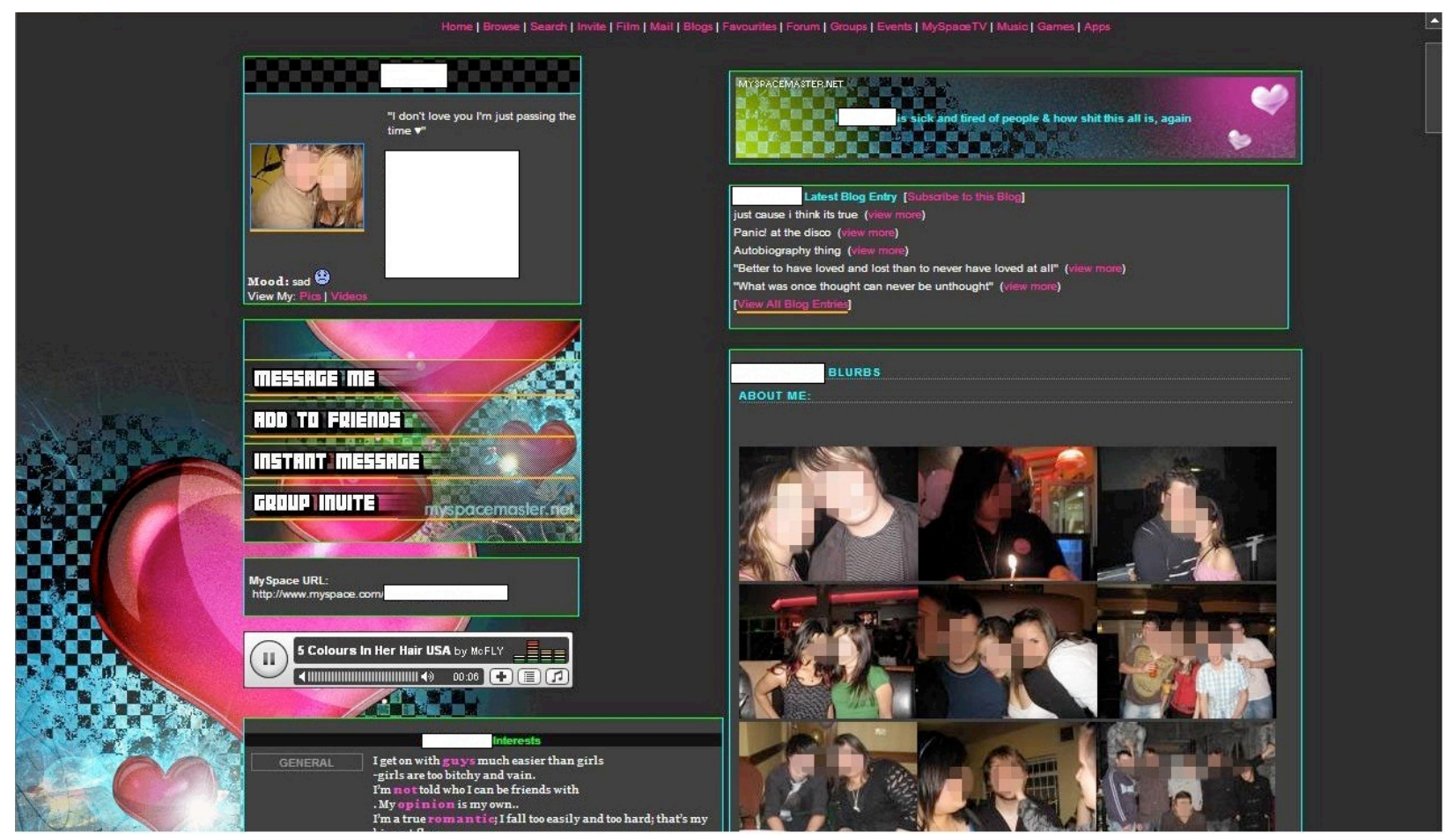

Figure 6 Screenshot of Julia's Second Profile Page. 
Figure 6 shows the continuation of the playful construction of the self in the first profile as Julia has changed her display name to 'I don't love you I'm just passing the time'. Again, this performs a distance from one potential audience - those who support alternative forms of MySpace practices. However, the most notable change to the profile is the addition of a number of photographs to the profile page. The blurb (which previously included the line 'where does anyone start when having to talk about themselves') has been replaced with a collage of photographs which cycle through a number of different images in a slideshow format. These photographs include a number of photographs of Julia (matched to the profile photograph) in a range of venues with a variety of different people. Figure 6 also shows changes to the song choice and profile background, which bolster the membership to a particular social group in MySpace.

There is a similar contradiction in this profile as with the previous profile page: Julia 'hates' to be like other members of MySpace, while at the same time the visual aspects of the profile suggest a high number of positive connections in MySpace. This contradiction provides a way of doing identity. This uses the difference across the profile changes as a way of cementing interest in the profile and embedding a narrative in the self. Perhaps one of the reasons for intervening with these moments of contradiction is due to the way that the self is never finished in MySpace and it requires to be seen as continuously moving and changing. The self is always 'in potential' and never finished both online and offline. This shows that movement and change are essential properties of the self in MySpace. It can be argued that the moment a MySpace user constitutes the self in MySpace they are responsible to keep it moving and changing, just as with real life situations and relations. In MySpace, this process requires the unique mediation of an imagined community of members. 
Extract 2 seems to further support the possibility of a mediated community that relies on the constant performance of a set of imagined connections as opposed to a community of people who are 'just there' (in the way that Marwick and boyd describe the possibility of an 'imagined audience'). Furthermore, Marwick and boyd (2010) explain how there is a possibility that each action has the ability to 'collapse' audiences into a single actions, but following this analysis it is also possible that a single action has the ability to 'extend' the connections to a potential audience. This distinction is also helpful in exploring the claim that new technologies also come with a new sense of distance. For MySpace users, it would appear that there is dilemma of closeness and distance that is embedded in the way that the self is negotiated and re-negotiated in the everyday use of the site.

\section{CONCLUSIONS}

Through the analysis of empirical data from MySpace profiles, this study has attempted to use a historical approach to identify current social practices. It is almost necessary to look at SNSs in this way as it is almost impossible to get any real purchase on the technology due to the way it is constantly changing. For example, as I write, Google have recently launched a new SNS

$($ Google +$)$ that has the potential to rival Facebook and perhaps Facebook, like MySpace, will soon witness a move to a wide spread movement to another SNS. What this shows, is that it is necessary to look at the 'past' uses of SNSs as it is almost impossible to capture the use of these sites in the present.

The current findings from MySpace can be applied to similar forms of new social networking technologies in four main ways: i) constant change is essential to the construction of the self in these spaces ii) despite the fluidity of the self there is still the ability to feel part of a 
coherent whole in SNSs iii) the self is essentially hoped-for in use of profile changes and iv) construction of the self requires a joint relationship between the visual and the textual in the profile. These findings will now be discussed in more detail.

Firstly, this research shows that the constant changes to the profile page are fundamental to the construction of the self in MySpace. While appearing to be somewhat wasteful, the changes are essential to the presentation of the online self by foregrounding a number of communicative possibilities. This shows that the Internet is not automatically a space for communication and each MySpace member is confronted with the task of constructing the self through the different aspects of the profile page. Users need communication to understand who they are (and who they can be) in this space. The micro-blogging site Twitter also has the same wasteful qualities, but, like MySpace, twitter relies on a set of anticipatory actions that are necessary to carve-out a space for communication. Therefore, the constant need to 'talk' is an essential component of this technology.

Secondly, the analysis of MySpace shows how we are not able to directly experiment with a number of social positions through activities like profile changing, but that the self exists in the spaces between these different selves (or profiles). This is due to the way that even though there is a high amount of dispersion across different sites and profiles, the self is still feels part of a coherent whole. The self is process that does not allow for a spatial comparison or sense of division. Consider one of Foucault's later definitions of self for further clarity of this idea:

It is not a substance. It is a form, and this form is not primarily or always identical to itself. You do not have the same sort of relationship to yourself when you constitute yourself as a political subject who goes to vote or speaks at a meeting and when you are 
seeking to fulfil your desires in a sexual relationship. Undoubtedly there are relationships and interferences between these different forms of subject; but we are not dealing with the same type of subject. In each case, one plays, one establishes a different relationship to oneself (Foucault, 2000: 290-291).

The above quote shows how the different selves do not collide because our experience involves an inherent multiplicity in the performance of the self. In MySpace, the different selves that are created in each profile page present an opportunity to experiment with the self in a variety of ways, tangled up in a variety of different meanings that cross over but do not crash into each other. In the different historical perspectives that have been applied to this technology, this concept offers a different argument to the 'dramaturgical' notion of the self (following Goffman). This shows a need to revisit how we conceptualise the self in these spaces where it could be beneficial to consider a following a range of theoretical positions.

Thirdly, the historical analysis of MySpace allows for a development of the ideas on the 'imagined audience' (Marwick and boyd, 2010). This paper argues that MySpace extracts demonstrated a community that cannot be said to act in any particular way (if we recall it is 'just there') and constituted what could be described as a mediated community. In a mediated community, one could describe these selves as fundamentally hoped-for as they relate to a desired form of self that is specifically crafted to appeal to an imagined sense of community. Therefore, the multiple forms of the self are hoped-for due to the construction of the self in terms of a felt sense of community in MySpace. In practice, the hoped-for self requires constructing a multitude of different forms of the self in order to align with the multiplicity of imagined community ties. 
Finally, the study of MySpace shows how the online self requires the use of both the visual and the textual aspects of the site. Thus, conceptions of the online body and the self should include the power of the visual as it does not just fill in the gaps in the discourse, but rather that they dissolve as separate entities in the MySpace page and form a communicative whole - one which could be interpreted as wastefulness, but is actually part of the ongoing attempt to forge a link with a particular version of the self in a complex set of relations with other users. The everyday use of MySpace involves a multifaceted relationship between self and community, real and imagined, online and offline, and most crucially, visual and textual ${ }^{6}$.

Historical research of this kind can promote vital discussion on the changing shape of the online social landscape. Following this paper, an investigation of Facebook (or other SNSs) should look to understand the site through a variety of modes of expression as with the visual and the textual in this article. It should also consider how different privacy constitutes a sense of different formation of community. On a broader scale, there is a need to look the complex way that communication technologies continue to mediate our everyday lives in diverse and intricate ways.

\section{ACKNOWLEDGEMENTS}

Thank you to Prof. Steven D. Brown and Dr. Abigail Locke for their advice on the analytic direction of this paper. I must also thank the reviewers and editors at Visual Communication for their insightful comments and guidance.

\section{NOTES}


1. Turkle was trained as a psychoanalyst and there is therefore an interest in 'authenticity'.

2. However, the majority of the users that featured in this sample were between 18 and 24 . MySpace users are typically found to be aged between 14 and 24 (boyd, 2006). Users who stated that they were below 18 have been excluded for this study.

3. Apart from those names that do not allow for recognition in any way, such as, 'It's a Casual Thing'.

4. However, this does mean that the findings cannot be generalised to the entirety of MySpace as there are a high number of users who communicate through private networks in MySpace. The reason for using public profiles, other than the ethical advantage, was to capture the communication from those people who used MySpace openly and had the potential to communicate with a variety of different people in MySpace.

5. Creamfields is a UK dance festival.

6. For a further on the broader power of the visual and the use of MySpace see Goodings and Brown, 2011.

\section{REFERENCES}

Alexa.com (2011). MySpace ranked $87^{\text {th }}$ in the world according to Alexa traffic ratings, URL (consulted, July 2011): http://www.alexa.com/siteinfo/myspace.com

Anderson, B. (1983). Imagined Communities: Reflections on the Origin and Spread of Nationalism. London: Verso. 
Antaki, C., Ardévol, E., Núñez, F. and Vayreda, A. 'For She Who Knows Who She Is: Managing Accountability in Online Forum Messages', Journal of Computer-Mediated Communication 11: 114-132.

Bargh, J. A., McKenna, K. Y. A. and Fitzsimons, G. M. (2002). 'Can You See The 'Real' Me? Activation and Expression of the True Self on The Internet', Journal of Social Issues 58 (1): $33-48$.

Bakardjieva, M. (2005) Internet Society: The Internet in Everyday Life. London: Sage.

Barthes, R. (1967). Elements of Semiology. London: Jonathan Cape.

Barthes, R. (1991). The Responsibility of Forms. Critical Essays on Music, Art and Representation. Berkeley: University of California Press.

Baudrillard, J. (1988). The Ecstasy of Communication (B. Schutze Translation). Semiotext Foreign Agents Series.

Bezemer, J. and Jewitt, C. (2009) 'Multimodal analysis' in L. Litosseliti (ed.), Research Methods in Linguistics. London: Continuum.

Bohnsack, R. (2008). 'The Interpretation of Pictures and the Documentary Method', Forum: Qualitative Social Research Sozialforschung 9(3): Art. 26.

Booth, P. (2008). 'Rereading Fandom: MySpace Character Personas and Narrative Identification', Critical Studies in Media Communication 25(5): 514-536.

boyd, d. (2006a). 'Friends, Friendsters, and Top 8: Writing Community into Being on Social Network Sites', First Monday 11(12), URL (consulted May, 2009): http://www.firstmonday.org/issues/issue11_12/boyd/index.html.

boyd, d. (2006b). 'A Blogger's Blog: Exploring the Definition of a Medium'. Reconstruction 6(4), URL (consulted May, 2009): http://www.danah.org/papers/ABloggersBlog.pdf. 
boyd, d. (2007). 'Why Youth (Heart) Social Network Sites: The Role of Networked Publics in Teenage Social Life', in D. Buckingham (eds) MacArthur Foundation Series on Digital Learning - Youth, Identity, and Digital Media Volume, pp. 119-142. Cambridge, MA: MIT Press.

boyd, d. and Ellison, N. B. (2007). 'Social Network Sites: Definition, History, and Scholarship', Journal of Computer-Mediated Communication 13(1), URL (consulted May, 2008): http://jcmc.indiana.edu/vol13/issue1/boyd.ellision.html.

boyd, d. and Heer, J. (2006). 'Profiles as Conversation: Networked identity performance on Friendster', in Proceedings of the Hawai'i International Conference on System Sciences (HICSS-39), Persistent Conversation Track, URL (consulted June, 2009): http://www.danah.org/papers/HICSS2006.pdf

Brown, S. D. (2001). 'Psychology and the Art of Living', Theory \& Psychology 11(2): 171-192.

Brown, S. D. and Stenner, P. (2009). Psychology without Foundations: History, Philosophy and Psychosocial theory. London: Sage.

Cheung, C. (2000). 'A Home on the Web: Presentation of Self on Personal Home Pages', in D. Gauntlett (ed.) Web.Studies: Rewiring Media Studies for the Digital Age, pp. 43 -52 London: Arnold.

Davies, B. and Harré, R. (1990). 'Positioning: The Discursive Production of Selves', Journal for the Theory of Social Behaviour 20: 43-63.

Davis, J. (2010). 'Architecture of the Personal Interactive Homepage: Constructing The Self In MySpace', New Media \& Society 12(7): 1103-1119.

Edwards, D. and Potter, J. (1992). Discursive Psychology. London: Sage. 
Ess, C. and the AoIR Ethics Working Committee (2002). Ethical Decision-Making and Internet Research: Recommendations from the Aoir Ethics Working Committee. URL (consulted, January 2005): http://aoir.org/reports/ethics.pdf.

Flicker, S., Haans, D. and Skinner, H.A. (2004). 'Ethical Dilemmas in Research on Internet Communities', Qualitative Health Research 14: 124 -134.

Foucault, M. (1982). This is Not a Pipe. California, University of California Press.

Foucault, M. (2000). Ethics: Essential works of Foucault 1954-1984, volume 1. Harmondsworth Press.

Goffman, E. (1959). The Presentation of Self in Everyday Life. London: Doubleday.

Goodings, L. (In Press). 'The Dilemma of Closeness and Distance: A Discursive Analysis of Wall Posting in MySpace', FQS.

Goodings, L. and Brown, S.D. (2011). 'Visuality and Textuality in MySpace Communication', in P. Reavey (ed.) Visual Psychologies. London: Routledge.

Goodings, L., Locke, A. and Brown, S.D. (2007) 'Social Networking Technology: Place and Identity in Mediated Communities', Journal of Community and Applied Social Psychology 17: 463-467.

Gergen, K. J. (1994). Realities and Relationships: Soundings in Social Construction. Cambridge, MA: Harvard University Press.

Greiffenhagen, C. and Watson, R. (2009). 'Visual Repairables: Analysing the Work of Repair in Human Computer Interaction', Visual Communication 8(1): 65-90.

Griffiths, M. and Whitty, M. (2010). 'Online behavioural Tracking in Internet Gambling Research: Ethical and Methodological Issues', International Journal of Internet Research Ethics 3(12): 104-117. 
Gross, R., Acquisti, A. and Heinz, H. J. III (2005). 'Information Revelation and Privacy in Online Social Networks', in Proceedings of the 2005 ACM workshop on Privacy in the Electronic Society, URL (consulted January, 2010): http://www.heinz.cmu.edu/ حacquisti/papers/privacy-facebook-gross-acquisti.pdf

Harper, R. (2010). Texture: Human Expression in the Age of Communication Overload. MIT Press.

Harré, R. (1983). Personal Being: A theory for individual psychology. Oxford: Blackwell.

Harré, R. (1998). The Singular Self: An Introduction to the Psychology of Personhood. London: Sage.

Harré, R. and van Langenhove, L. (1991). 'Varieties of Positioning'. Journal for the Theory of Social Behaviour 21(4): 393-407.

Hinduja, S., \& Patchin, J. W. (2008). 'Personal Information of Adolescence on the Internet: A Quantitative Content Analysis of MySpace', Journal of Adolescence 31(1): 125-146.

Jewitt, C. (ed.) (2009) The Routledge Handbook of Multimodal Analysis. London: Routledge.

Jewitt, C., Leeuwen, T. V., Scollon, R. and Triggs, T. (2002). 'Editorial', Visual Communication 1(1): 5-8.

Jewitt, C. and Triggs, T. (2006). 'Screens and The Social Landscape', Visual Communication 5(2): 131-140.

Knoblauch, H., Beer, A., Laurier, E., Petschke, S. and Schnettler, B. (2008). 'Visual Analysis: New Developments in the Interpretative Analysis of Video and Photography, Forum: Qualitative Social Research Sozialforschung 9 (3): Art. 14

Lampe, C., Ellison, N. and Steinfield, C. (2007). 'A familiar Face(book): Profile Elements as 
Signals in An Online Social Network', in Proceedings of the SIGCHI conference on Human factors in computing systems (CHI '07), URL (consulted April, 2010) http://doi.acm.org/10.1145/1240624.1240695

Lanier, J. (2010). You are Not a Gadget: A manifesto. London: Allen Lane.

Lave, J. and Wenger, E. (1991). Situated Learning: Legitimate Peripheral Participation. Cambridge: Cambridge University Press.

Leary, T. (1999) Turn On, Tune In, Drop Out (6 $6^{\text {th }}$ edn). Berkeley: Ronin Publishing.

Malinowski, B. (1923). 'The Problem of Meaning in Primitive Languages', in C. K. Ogden and I. A. Richards (ed.) The Meaning of Meaning, pp. 296-346. London: Routledge.

Marwick, A. E. (2008). 'To Catch a Predator? The MySpace Moral Panic', First Monday 13(6), URL (consulted May, 2009): http://firstmonday.org/htbin/cgiwrap/bin/ojs/index.php/fm/article/ view/2152/1966

Marwick, A. E. and boyd, D. (2010). 'I tweet honestly, I tweet passionately: Twitter Users, Content Collapse, and the Imagined Community', New Media \& Society 13(1): 114-133.

Moreno, M. A., Parks, M. and Richardson, L. P. (2007). 'Why are Adolescents Showing The World About Their Health Risk Behaviours on MySpace?' MedGenMed 9(4): 9, URL (consulted July, 2008): http://www.ncbi.nlm.nih.gov/pmc/articles/PMC2234280/

Norris, S. (2002). 'The Implications of Visual Research for Discourse Analysis: Transcription Beyond Language', Visual Communication 1(1): 97-121.

Pink, S. (2007). Doing Visual Ethnography. London: Sage.

Pink, S. (2008). 'Mobilising Visual Ethnography: Making Routes, Making Place and Making Images', Forum: Qualitative Social Research Sozialforschung 9(3): Art. 36.

Plant, S. (1997). Zeros and Ones: Digital Women and the New Technoculture. Doubleday: New York 
Potter, J. (1996). Representing Reality: Discourse, Rhetoric and Social Construction. London: Sage.

Potter, J. and Wetherell, M. (1987). Discourse and Social Psychology Beyond Attitudes and Behaviour. London: Sage.

Reavey, P. (ed.) (2011) Visual Psychologies. London: Routledge.

Rheingold, H. (1993). The Virtual Community: Homesteading on the Electrical Frontier. Reading: Addison Wesley.

Robinson, L. (2007). 'The Cyberself: The Self-ing Project Goes Online, Symbolic Interaction in The Digital Age', New Media and Society 9(1): 12-28.

Siibak, A. (2009). 'Constructing the Self through Photo Selection - Visual Impression Management on Social Networking Websites', Cyberpsychology: Journal of Psychosocial Research on Cyberspace 3(1), URL (consulted April, 2010): http://www.cyberpsychology.eu/view.php?cisloclanku=2009061501

Thelwall, M. (2008). 'Social Networks Gender and Friending: An analysis of MySpace Member Profiles'. Journal of the American Society for Information Science and Technology 59(8): 1321-1330.

Thelwall, M. (2009). 'MySpace Comments', Online Information Review 33(1): 58-76.

Thrift, N. (2003). 'Practicing Ethics', in M. Pryke., G. Rose, \& S. Whatmore (ed.) Using Social Theory: Thinking Through Research, pp.105-121. London: Sage Publications.

Turkle, S. (1995). Life on the Screen: Identity in The Age of The Internet. New York: Simon \& Schuster.

Van Doorn, N. (2010). 'The Ties That Bind: The Networked Performance of Gender, Sexuality and Friendship on MySpace', New Media \& Society 12(4): 583-602. 
Whttiy, M. T. (2008). 'Revealing the 'Real' Me, Searching for The 'Actual' You; Presentations of Self on An Internet Dating Site', Computers in Human Behaviour 24(4): 1707-1723.

Whynn, E. and Katz, J. (1997). 'Hyperbole over Cyberspace: Self-presentation and social boundaries in Internet Home Pages and discourse', The Information Society: An International Journal 13(4): 297-328. 